\title{
Towards a regional ocean forecasting system for the IBI (Iberia-Biscay-Ireland area): developments and improvements within the ECOOP project framework
}

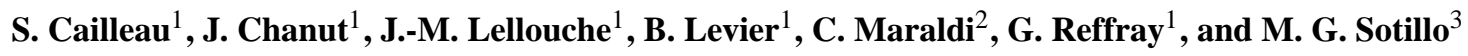 \\ ${ }^{1}$ Mercator Océan, Toulouse, France \\ ${ }^{2}$ Service Hydrographique et Océanographique de la Marine (SHOM), Toulouse, France \\ ${ }^{3}$ Puertos del Estado (PdE), Madrid, Spain
}

Correspondence to: S. Cailleau (sylvain.cailleau@mercator-ocean.fr)

Received: 30 March 2011 - Published in Ocean Sci. Discuss.: 7 September 2011

Revised: 27 February 2012 - Accepted: 28 February 2012 - Published: 8 March 2012

\begin{abstract}
The regional ocean operational system remains a key element in downscaling from large scale (global or basin scale) systems to coastal ones. It enables the transition between systems in which the resolution and the resolved physics are quite different. Indeed, coastal applications need a system to predict local high frequency events (inferior to the day) such as storm surges, while deep sea applications need a system to predict large scale lower frequency ocean features. In the framework of the ECOOP project, a regional system for the Iberia-Biscay-Ireland area has been upgraded from an existing V0 version to a V2. This paper focuses on the improvements from the V1 system, for which the physics are close to a large scale basin system, to the V2 for which the physics are more adapted to shelf and coastal issues. Strong developments such as higher regional physics resolution in the NEMO Ocean General Circulation Model for tides, non linear free surface and adapted vertical mixing schemes among others have been implemented in the V2 version. Thus, regional thermal fronts due to tidal mixing now appear in the latest version solution and are quite well positioned. Moreover, simulation of the stratification in shelf areas is also improved in the V2.
\end{abstract}

\section{Introduction}

The aim of the ECOOP Project (www.ecoop.eu) consists in building a Pan-European ocean operational system of observation and forecasting. Five areas are considered: the Baltic Sea $(\mathrm{BOOS}=$ Baltic sea Ocean Operational System), the North-west shelf $(\mathrm{NOOS}=$ North-west shelf Ocean Operational System), the Iberia-BiscayIreland area $($ IBIROOS $=$ Iberia-Biscay-Ireland Regional Ocean Operational System) the Mediterranean Sea $(\mathrm{MOON}=$ Mediterranean Ocean Operational system $)$ and the Black Sea (BSGOOS = Black Sea Global Ocean Operational System). Each area is composed of regional systems and embedded coastal ones.

At the beginning of the project, a first general inventory of existing European ocean systems was carried out, but at the time there were neither common standards (in terms of output data, validation diagnostics, etc.), nor many connections between systems. Furthermore, there was not much documentation on data for users available from these systems, or the way to download it. At this stage, systems were considered to be the V0 version in the ECOOP Project.

The next step of ECOOP was for each system to upgrade and integrate by improving downscaling from regional to coastal systems in order to reach the V1 version of systems. These V1 systems ran all together for a 6-month operational experiment (TOP: Target Operational Period). During the TOP users could get data and corresponding information through the central ECOOP portal EuroMISS. Users could also directly display data in the ECOOP website via the DQV tool (Dynamic Quick View, a Google earth application), and could quickly assess it thanks to the validation page of the ECOOP website too.

Finally, the following V2 version of each system was improved in order to reduce V1 uncertainties. Moreover, Mercator Ocean is still upgrading this V2 system version in the framework of the EU FP7 project MyOcean (www.myocean. eu.org). 


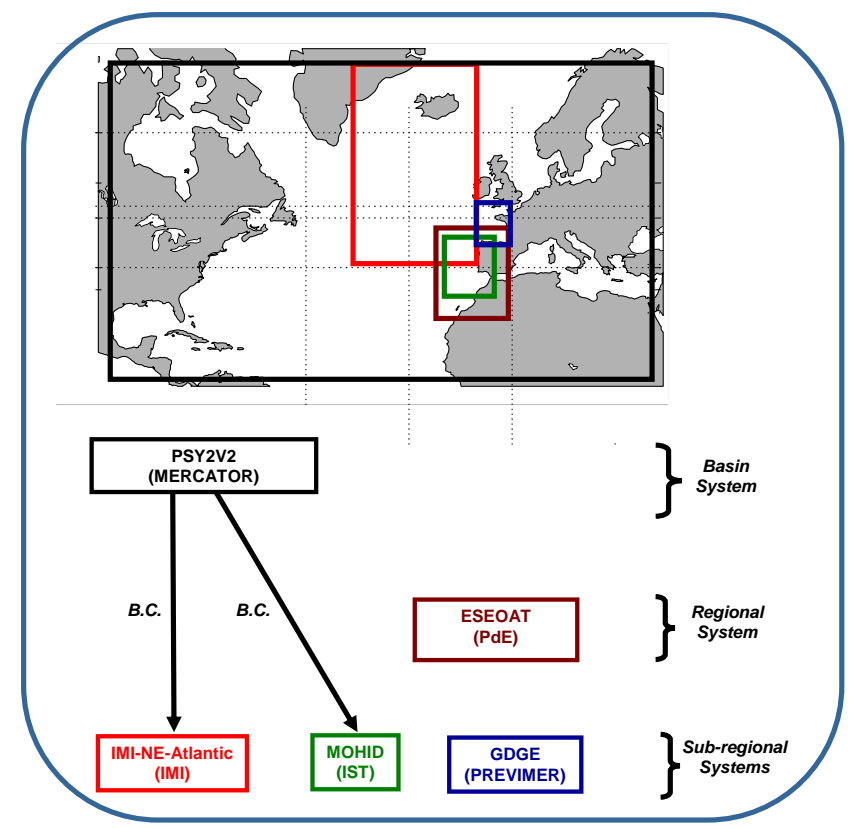

Fig. 1. Downscalling scheme of integrated IBIROOS V0 (B.C. = Boundary Conditions).

In this paper, we focus on the evolution of the regional Mercator Ocean IBI forecasting system from V0 to V2, with particular attention to the final V2 version. The reader has to distinguish the stand-alone IBI regional system (Mercator Ocean) from the ECOOP IBI integrated system which includes the regional system as well as the coastal ones embedded in it.

Here we consider the Mercator Ocean IBI system only as the regional system.

The first part is dedicated to the description of each regional IBI system version, whereas the second one covers to the comparison between V1 and V2 system solutions. The objective of this second part is not an exhaustive validation, we have rather focused on some the most obvious improvements between the two versions.

\section{Description of the regional Mercator Ocean System V0}

Five partners have been involved in the IBIROOS integrated system: Mercator Ocean (France), PdE (Puertos del Estado, Spain), IST (Instituto Superior Técnico, Portugal), PREVIMER (France) and IMI (Irish Marine Institute, Ireland). The integrated IBIROOS V0 system consists in an inventory of existing European regional and coastal systems in the IBI area. It is composed of 5 different elements (see Fig. 1): a basin system for the North Atlantic ocean: PSY2V2 (Mercator Ocean), a Regional System, covering the entire Iberian area: ESEOAT (PdE, Sotillo et al., 2007) and three Sub- regional Systems covering respectively the Irish shelf system IMI-NE-Atlantic (IMI), the bay of Biscay and the Western channel system: GDGE (PREVIMER), and the Iberian coasts system: MOHID (IST). PSY2V2 provides boundary conditions to the IMI and IST systems, whereas the PdE and PREVIMER forecast systems are independent and, have no link with the rest of components of the ECOOP IBIROOS system. The downscaling scheme is not complete and this first global IBIROOS V0 system is not integrated. The improvement of connections between regional and coastal systems (e.g. here in the IBI area) is one of the main tasks in order to obtain an integrated IBIROOS V1 ready for the TOP experiment.

The regional Mercator Ocean IBI-V0 (PSY2V2) model configuration is based on the OPA8.1 Ocean General Circulation Model (Madec et al., 1998), a general circulation model developed at LOCEAN (Paris). The rigid lid hypothesis is applied at the surface in order to filter fast external gravity waves which the model cannot solve.

The model configuration covers the North Atlantic ocean (between $9^{\circ} \mathrm{N}$ and $70^{\circ} \mathrm{N}$ ) embedding the IBI area. The primitive equations are discretized on a $1 / 15^{\circ}(\sim 5 \mathrm{~km}$ in IBI) irregular rotated grid of Mercator and on 43 z-levels in the vertical, with a resolution decreasing from $\sim 6 \mathrm{~m}$ near the surface to more than $300 \mathrm{~m}$ in the abyssal plain. A simple full cell representation of the bathymetry is used. The bathymetry is derived from the ETOPO2 data set. Initial conditions for temperature and salinity are derived from climatology of Reynaud et al. (1998) in Atlantic and MEDATLAS (http://www.ifremer.fr/medar) in the Mediterranean Sea.

Meteorological fluxes from the European Centre for Medium-Range Weather Forecasts (ECMWF) with a daily and $0.25 \times 0.25^{\circ}$ resolution are used to force the model. Surface fresh water and heat fluxes are directly applied to the surface model. The short wave radiation penetrates the surface layer according to a simple extension law (2 extension lengths), without any dependence on ocean colour. The model also includes river inputs from a monthly climatology runoff built by averaging data from the Global Runoff Data Center (http://grdc.bafg.de). Buffer zones are used at the closed boundaries with a damping toward the T-S climatology of Reynaud et al. (1998).

Regarding data assimilation, a multivariate multi data optimal method is applied. The statistical representation of the forecast error is established analytically in two dimensions (horizontal) and from EOFs in one dimension (vertical). Altimetric sea level anomaly (Jason-1, Envisat, GEOSAT Follow On), SST Reynolds and in situ T/S vertical profiles are assimilated in a fully multivariate way. $\mathrm{T} / \mathrm{S}$ profiles come from the CORIOLIS network (http://www.coriolis.eu.org) which gathers several buoy and ship data sets.

Finally, for the operational protocol, each Wednesday (day (D) of run), IBI-V0 provides one week of hindcast (best estimates: with assimilation of full observation data sets) from D-14 to D-7, one week of nowcast from D-7 to D 
Table 1. Description of regional IBIROOS-V0: PSY2V2.

\begin{tabular}{|c|c|}
\hline \multicolumn{2}{|l|}{ REGIONAL IBIROOS-V0: PSY2V2 } \\
\hline Domain & North Atlantic: 9 to $70^{\circ} \mathrm{N}\left(20^{\circ} \mathrm{W} / 0\right.$ and $\left.30^{\circ} \mathrm{N} / 52^{\circ} \mathrm{N}\right)$ \\
\hline \multicolumn{2}{|l|}{ PHYSICS } \\
\hline Calculation Code & OPA 8.1 (Primitive Equations) (Madec et al., 1998) \\
\hline Output frequency & Daily \\
\hline Horizontal grid & Rotated Mercator $1 / 15^{\circ}$ grid in Atlantic, $1 / 16^{\circ}$ in Mediterranean sea \\
\hline Vertical grid & $\begin{array}{l}\text { - } 43 \text { vertical levels (6 to } 300 \mathrm{~m} \text { ) } \\
\text { - Rigid lid surface } \\
\text { - Full cells at the bottom }\end{array}$ \\
\hline Bathymetry & ETOPO2 \\
\hline Surface Forcings & $\begin{array}{l}\text { - Direct atmospheric flux forcings } \\
\text { - Daily mean ECMWF analysis \& forecasts } \\
\text { - Monthly run off } \\
\text { - Short wave radiation penetration with } 2 \text { band scheme }\end{array}$ \\
\hline Boundary Conditions & $\begin{array}{l}\text { - Buffer zone (closed boundary with T-S damping) } \\
\text { - T-S damping towards climatology of Reynaud et al. (1998) }\end{array}$ \\
\hline Lateral Friction & Partial slip lateral boundary friction condition \\
\hline Bottom Friction & Non linear bottom friction \\
\hline Horizontal Diffusion for the Dynamics & Biharmonic diffusion \\
\hline Horizontal Diffusion for the Tracers & Isopycnal laplacian diffusion \\
\hline Vertical Mixing & TKE vertical mixing model (Gaspar et al., 1990) \\
\hline Tide & No tide \\
\hline \multicolumn{2}{|l|}{ BIOLOGY } \\
\hline & No Biology \\
\hline \multicolumn{2}{|l|}{ ASSIMILATION } \\
\hline Method & Multivariate Multidata Optimal Interpolation \\
\hline Statistical Representation of the Forecast Error & 2-D analytical (horizontal) + EOFs 1-D (vertical) \\
\hline Assimilated Data & $\begin{array}{l}\text { Altimetric Sea Level Anomaly (Jason-1, Envisat, GEOSAT Follow On), } \\
\text { SST Reynolds and in situ T/S vertical profiles }\end{array}$ \\
\hline
\end{tabular}

(with assimilation of available observation data sets) and two weeks of forecasts from D to D+14. This V0 description is summarized in Table 1.

\section{Description of the regional Mercator Ocean System V1}

The integrated IBIROOS V1 system is composed of 4 different elements (see Fig. 2): a basin system of the North Atlantic ocean: PSY2V3 (Mercator Ocean), and three Subregional Systems covering respectively: the Irish shelf: IMINE-Atlantic (IMI), the bay of Biscay and the Western chan- nel: MANGA (PREVIMER), and the Iberian coasts: $M O$ $H I D$ (IST). At this step, the IBIROOS V1 is fully integrated: PSY2V3 provides boundary conditions to the three other sub-regional systems in real time via Mercator Ocean OpenDAP. It can be noted that in the V1 there is only one regional system which provides boundary conditions and initial conditions to the 3 other coastal systems. The PdE system ESEOAT is no longer present in this integrated IBIROOS V1. For ECOOP, PdE and Mercator Ocean worked together on validation tools and on the development of the next version of the regional IBIROOS-V2. This collaboration is still ongoing and is strengthening within the MyOcean EU Project. 


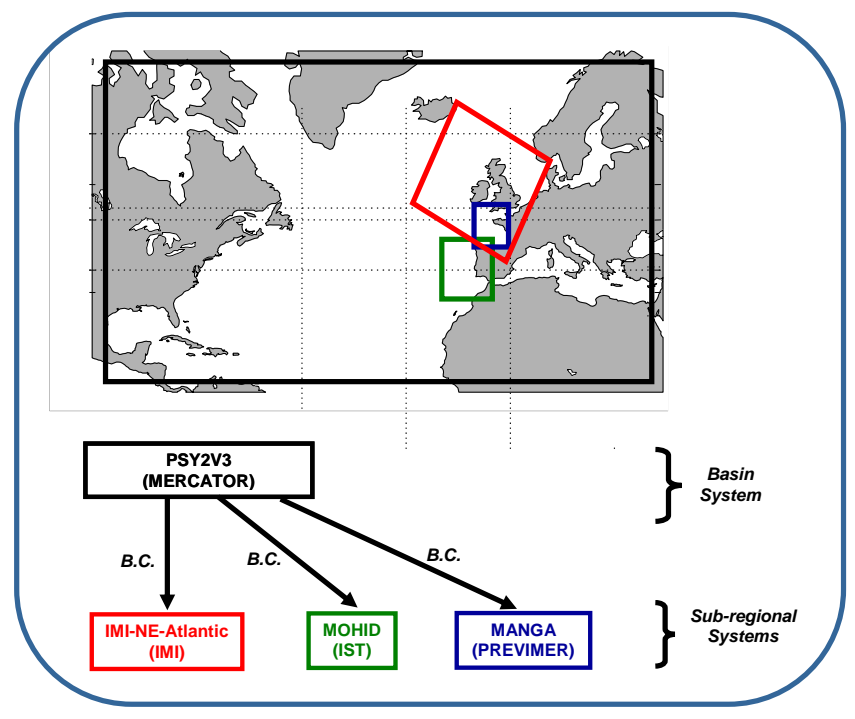

Fig. 2. Downscalling scheme of integrated IBIROOS V1 (B.C. = Boundary Conditions).

The regional Mercator Ocean IBI-V1 (PSY2V3) model configuration is based on the NEMO1.09 Ocean General Circulation Model (Madec et al., 1998; Madec, 2008). The linear free surface hypothesis is applied at the surface and only filters fast external gravity waves this model cannot solve.

The model configuration covers the North Atlantic Ocean between $20^{\circ} \mathrm{N}$ and $80^{\circ} \mathrm{N}$, embedding the IBI area. The primitive equations are discretized on a $1 / 12^{\circ}(\sim 6 \mathrm{~km}$ in IBI) global tripolar horizontal irregular ORCA grid used by NEMO and on 50 z-levels in the vertical, with a resolution decreasing from $\sim 1 \mathrm{~m}$ near the surface to more than $400 \mathrm{~m}$ in the abyssal plain.

Partial step representation of the bathymetry is used, which improves the model solution in the North Atlantic Ocean (Barnier et al., 2006). The bathymetry is derived from the ETOPO2 data set. Initial conditions for temperature and salinity are derived from the Levitus climatology. Forcings and operational protocols are the same as in the previous system version.

Regarding data assimilation, a multivariate multidata Singular Evolutive Extended Kalman filter (SEEK filter, Pham et al., 1998) is used. The forecast error covariances are represented by 3-D modes from a set of anomalies (statistical approach). Altimetric sea level anomaly (Jason-1, Envisat, GEOSAT Follow On), Reynolds SST (RTG) and in situ T/S vertical profiles (CORIOLIS network) are assimilated in a fully multivariate way. This description of V1 version is summarized in Table 2.

This V1 version constitutes the baseline IBI regional system for the 6-month ECOOP TOP experiment. For this TOP exercise, IBI-V1 hindcasts and forecasts were available through the ECOOP central portal EuroMISS in real time and were used as boundary conditions and initial conditions by the coastal systems embedded in IBI-V1 following the downscaling scheme in Fig. 2. As it is shown in Fig. 3, on the ECOOP website, users, during the TOP experiment, could display IBI-V1 outputs thanks to the Dynamics Quick View (a Google Earth application developed in the framework of ECOOP). Finally, users could also assess the quality of IBI-V1 hindcasts and forecasts through the ECOOP validation web page, where modelled SST was compared to the satellite SST ODYSSEA, http://cersat.ifremer.fr/Data/Discovery/By-parameter/ Sea-surface-temperature/ODYSSEA-Global-SST-Analysis, (see Fig. 4).

\section{Description of the regional Mercator Ocean System V2}

The integrated IBIROOS V2 system comprises a group of 4 different components with an extra basin system (IBI-V1 described above) used to provide OBCs to the IMI-NE-Atlantic system and to the new Mercator Ocean IBI-V2 (IBI36) system (see Fig. 5). The latter embeds three Sub-regional Systems covering respectively: the Irish shelf system IMI-NEAtlantic (IMI Irish Marine Institute), the bay of Biscay and Western channel system MANGA (PREVIMER), and the Iberian coasts system MOHID (IST). It should be noted that this V2 integrated system was not ready for the ECOOP project since IBI36 was not fully operational until spring 2011 (within the MyOcean Project framework).

The integrated IBIROOS V2 version not only incorporates improvements of the already existing V1 base-line regional and coastal systems, but also the generation of new forecast systems. IBIROOS V2 must be more accurate of course, must include more physical and ecosystem processes and must add a better assimilation scheme. As in previous sections, we give here a description of the Mercator Ocean Regional IBI system V2, which will soon provide boundaries and/or initial conditions for the sub-systems. A summary of the characteristics of the system is given in Table 3.

The regional Mercator Ocean IBI-V2 (IBI36) is based on the NEMO/OPA9 Ocean General Circulation Model (Madec et al., 1998; Madec, 2008). In order to allow fast external gravity waves, a "filtered" free surface formulation has been replaced by a time-splitting scheme of Griffies and Pacanowski (2001): the barotropic part of the dynamical equations is integrated explicitly with a short time step whereas depth varying prognostic variables (baroclinic velocities and tracers) that evolve more slowly are solved with a larger time step (Chanut et al., 2008). The linear free surface formulation has also been replaced by the non-linear free surface to allow a good representation of tidal waves in coastal regions where their amplitude is large compared to the local depth (Levier et al., 2007). The vertical turbulent mixing exchanges are estimated from the Generic Length Scale (GLS) model (Umlauf and Burchard, 2003). This model resolves a prognostic equation for turbulent kinetic energy and 
Table 2. Description of regional IBIROOS-V1: PSY2V3. Differences between V1 and V0 versions are written in bold characters.

\begin{tabular}{|c|c|}
\hline \multicolumn{2}{|l|}{ REGIONAL IBIROOS-V1: PSY2V3 } \\
\hline Domain & North Atlantic: $20^{\circ} \mathbf{S}$ to $80^{\circ} \mathrm{N}$ \\
\hline \multicolumn{2}{|l|}{ PHYSICS } \\
\hline Calculation Code & NEMO 1.09 (Primitive Equations) (Madec et al., 2008) \\
\hline Output frequency & Daily \\
\hline Horizontal grid & Tripolar ORCA grid $1 / 12^{\circ}$ \\
\hline Vertical grid & $\begin{array}{l}\text { - } 50 \text { vertical levels }(1 \text { to } 480 \mathrm{~m}) \\
\text { - Free linearized filtered surface } \\
\text { - Partial steps at the bottom }\end{array}$ \\
\hline Bathymetry & ETOPO2 \\
\hline Surface Forcings & $\begin{array}{l}\text { - Bulk formula: CLIO (Oberhuber, 1988) } \\
\text { - Daily mean ECMWF analysis \& forecasts } \\
\text { - Monthly run off } \\
\text { - Short wave radiation penetration with } 2 \text { band scheme }\end{array}$ \\
\hline Boundary Conditions & $\begin{array}{l}\text { - Buffer zone (closed boundary with T-S damping) } \\
\text { - T-S damping towards climatology of Reynaud et al. (1998) }\end{array}$ \\
\hline Lateral Friction & Partial slip lateral boundary friction condition \\
\hline Bottom Friction & Non linear bottom friction \\
\hline Horizontal Diffusion for the Dynamics & Biharmonic diffusion \\
\hline Horizontal Diffusion for the Tracers & Isopycnal laplacian diffusion \\
\hline Vertical Mixing & TKE vertical mixing model (Gaspar et al., 1990) \\
\hline Tide & No tide \\
\hline \multicolumn{2}{|l|}{ BIOLOGY } \\
\hline & No Biology \\
\hline \multicolumn{2}{|l|}{ ASSIMILATION } \\
\hline Method & Multivariate multidata SEEK filter \\
\hline Statistical Representation of the Forecast Error & EOFs 3-D from a set of anomalies \\
\hline Assimilated Data & $\begin{array}{l}\text { Altimetric Sea Level Anomaly (Jason-1, Envisat, GEOSAT Follow On), } \\
\text { SST Reynolds and in situ T/S vertical profiles }\end{array}$ \\
\hline
\end{tabular}

another for a generic length scale (mixing length, dissipation rate, etc.). Thus, commonly used closure schemes can be considered: Mellor-Yamada (1982), k- $\varepsilon$ (Rodi, 1987) or $\mathrm{k}-\omega$ (Wilcox, 1988). The turbulent viscosities and diffusivities are calculated by means of these two prognostic quantities but also thanks to stability functions (Canuto et al., 2001). This turbulent closure scheme is able to control unstable cases as convection because of the capacity of these stability functions to reach very high values in such situations. For our applications, we used the $\mathrm{k}-\varepsilon$ model. The surface and bottom values are calculated thanks to a Neumann condition. At the surface, the wave effect is considered (Craig and Banner, 1994).
The model domain covers part of the North East Atlantic ocean, going from the Canary Islands to Iceland. It encompasses also part of the Western Mediterranean Sea and the North Sea, reaching to the Skagerrak Strait that connects the Baltic Sea to the North Sea. The primitive equations are discretized on a $1 / 36^{\circ}(\sim 2 \mathrm{~km})$ curvilinear grid and on 50 z-levels in the vertical. Vertical resolution decreases from $\sim 1 \mathrm{~m}$ near the surface to more than $400 \mathrm{~m}$ in the abyssal plain.

Preliminary tests had been carried out on other Mercator Ocean models with both vertical resolutions, $46 \mathrm{z}$-level in the $\mathrm{V} 0$ and 50 z-levels in the V1 and V2, and it had been shown that the Eckman layer as well as the diurnal cycle of SST 


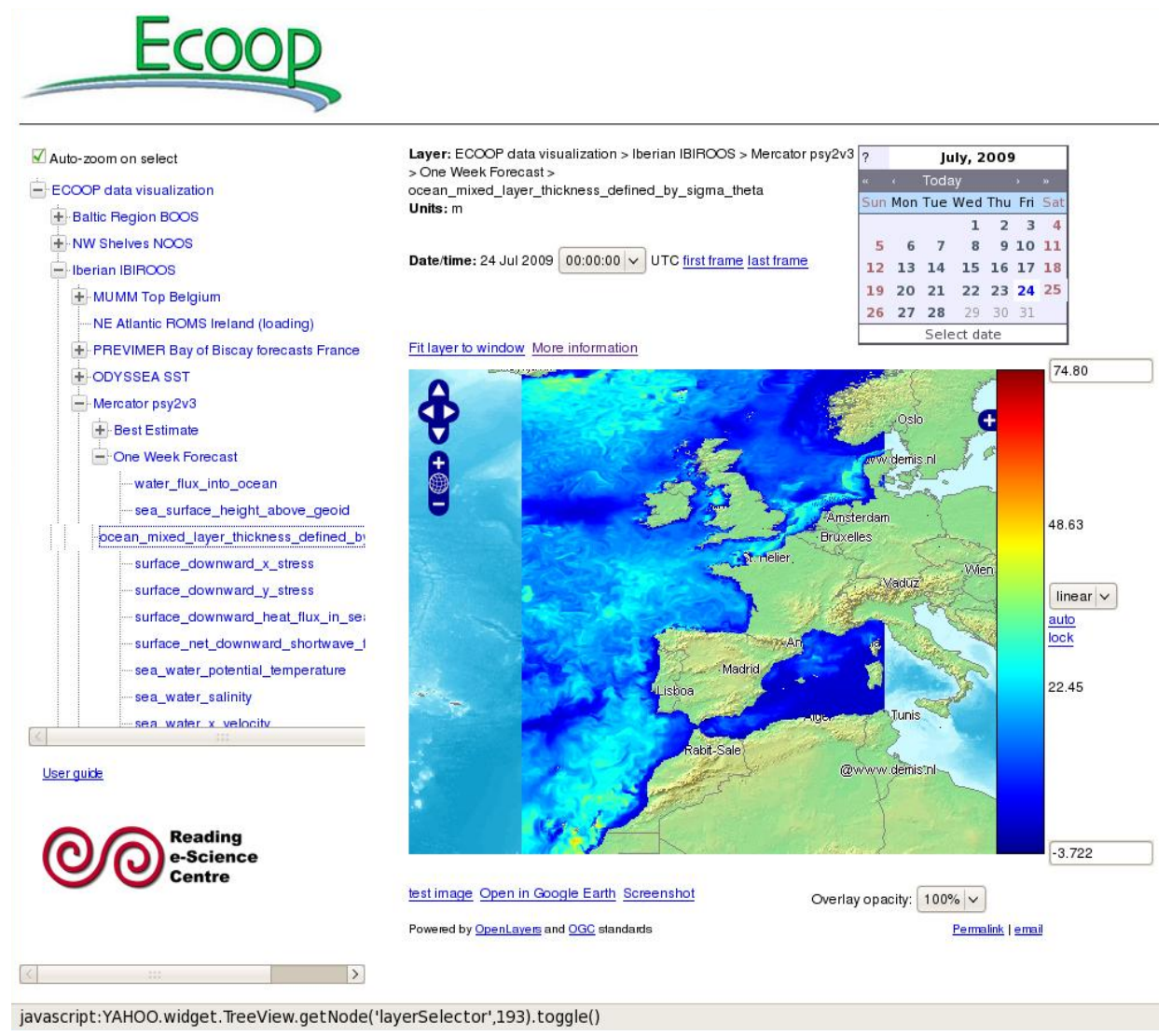

Fig. 3. Dynamic Quick Viewer to display the forecasts of the ECOOP operational systems: e.g. for IBI regional system.

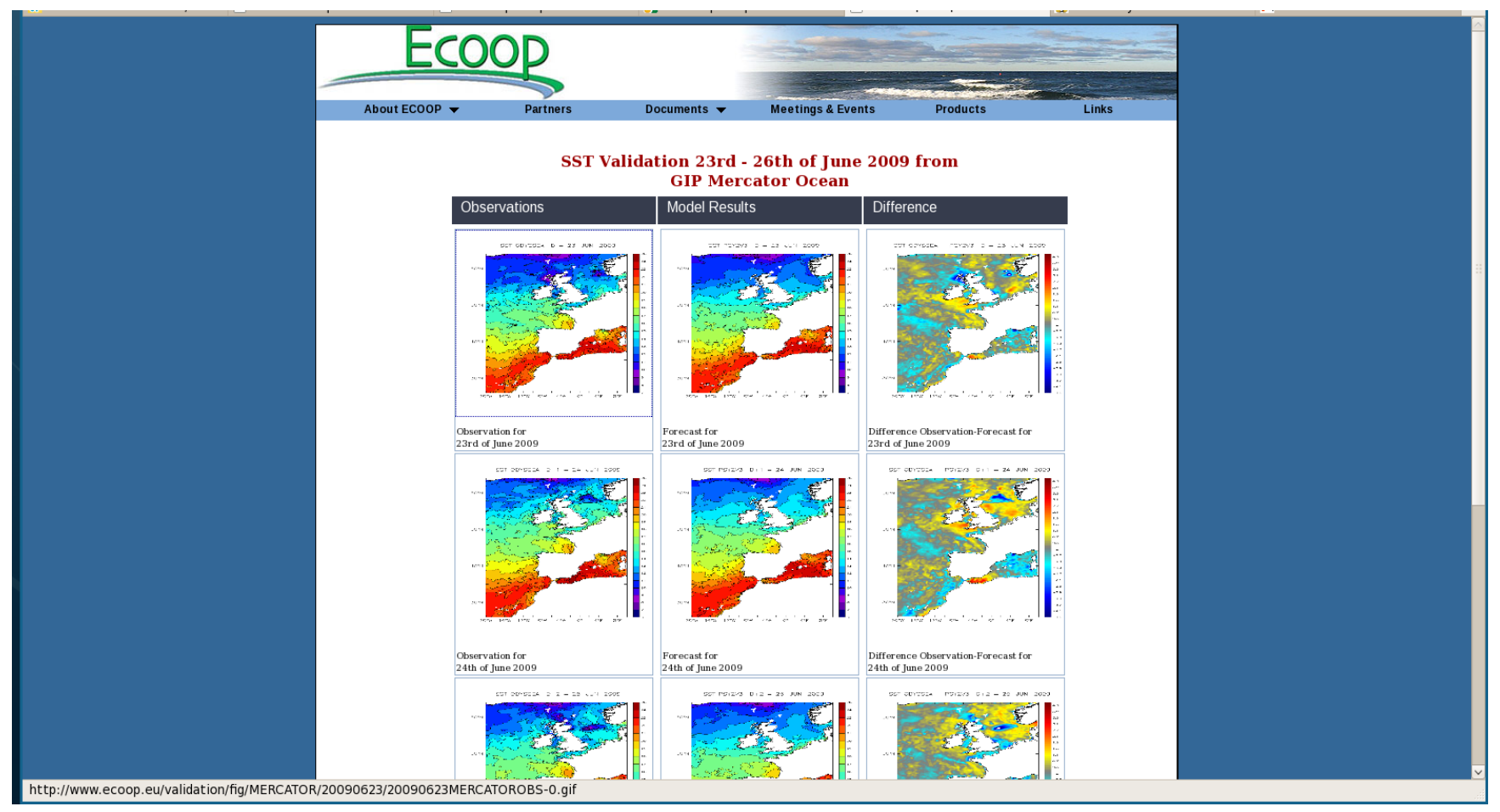

Fig. 4. ECOOP Validation webpage: e.g. for IBI regional system. 


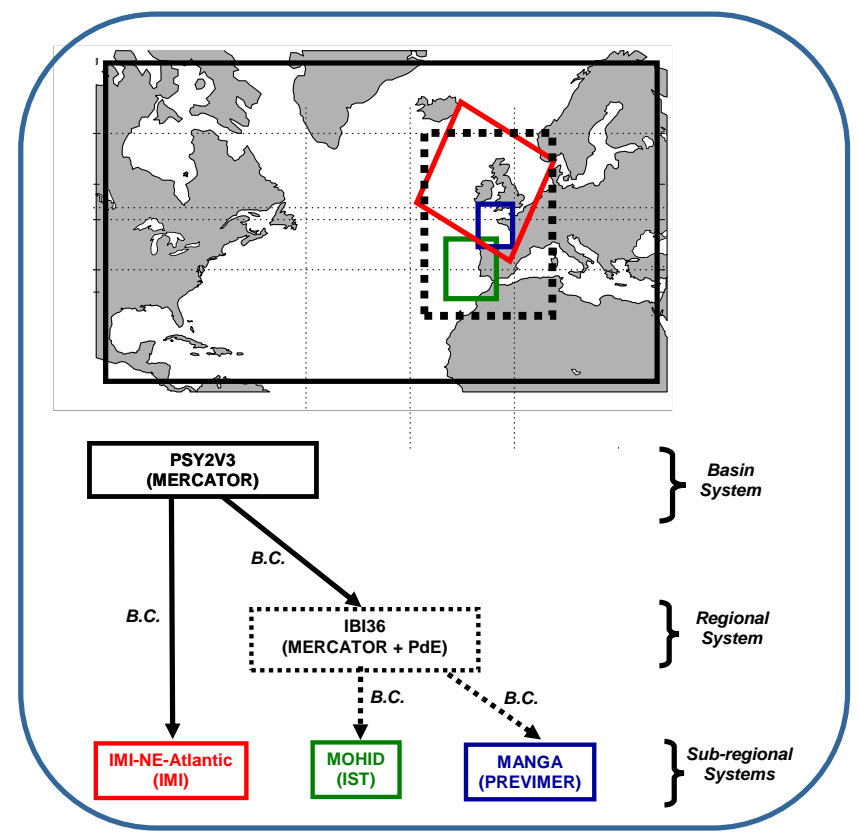

Fig. 5. Downscalling scheme planned for integrated IBIROOS V2 but still not operational for ECOOP (B.C. = Boundary Conditions).

have been better solved. Moreover, as V2 is forced by high frequency 3-hourly atmospheric fluxes (as described below), thus the diurnal cycle of SST is quite well solved thanks to the $50 \mathrm{z}$-level grid. Bernie et al. (2005) showed that $1 \mathrm{~m}$ vertical resolution at the surface was the minimum resolution to correctly resolve the diurnal cycle. Moreover, in summer, the stratification is very strong over the shelf when the thermocline can reach only a few meters. So this also can justify a one vertical meter resolution. And finally, as Burchard (2001) has shown, the parameterization of the wave breaking effect in the mixing in the superficial layers depends on the vertical resolution. This effect also needs high resolution (even less than $1 \mathrm{~m}$ ) to be taken into account.

A partial step representation of the bathymetry is used. The bathymetry is derived from the 30 arc-second resolution GEBCO 08 data set (Becker et al., 2009) merged with regional bathymetry provided by IFREMER, the French Navy (SHOM, Service Hydrographique et Océanographique de la Marine) and the NOOS community (North West Shelf Operational Oceanographic System, http://www.noos.cc).

Regarding atmospheric forcings, meteorological fields from the European Centre for Medium-Range Weather Forecasts $(\mathrm{ECMWF})$ with a 3-hourly and $0.25 \times 0.25^{\circ}$ resolution are used to force the model. According to Bernie et al. (2005), this time resolution is enough to solve diurnal variations of SST. Fresh water and heat surface fluxes are computed from CORE bulk formulae (Large and Yeager, 2004) using a set of atmospheric variables such as $2-\mathrm{m}$ air temperature, precipitation, relative humidity and radiative surface heat fluxes. Atmospheric pressure and wind stress fields are also used to force the momentum equations. It should be noted that solar heating flux is not evenly distributed through the depth of the top model layers. Instead, the short wave radiation penetrates the surface layer according to an extension law whose extinction coefficient is dependent on the ocean colour. This factor is needed to be considered in order to correctly simulate diurnal cycle in the surface oceans (Dai and Trenberth, 2004). In this specific model set-up, a monthly ocean colour climatology based on SeaWiFS data was used for this purpose. Astronomical tidal forcing is also included. It also includes river inputs from a monthly climatology runoff built by averaging data from the Global Runoff Data Center (http://grdc.bafg.de) and the French hydrographic database "Banque Hydro" (http:// hydro.eaufrance.fr). Thirty-five major rivers have been taken into account. The monthly climatology of fresh water transports has been applied to the system at each model grid point corresponding to a river mouth. It works as an open boundary segment, where we just specify the river transport (barotropic velocity with salinity $=0$ ) since we have no available data about temperature, salinity and baroclinic velocity of fresh water from the rivers. For the next version of IBI system, we are updating the runoff forcing by using a merge of daily hindcast, forecast and observation runoff data. Hindcasts and forecasts are provided by the E-HYPE hydrological model from SMHI and observations are provided by PREVIMER.

Temperature, salinity and sea surface heights from IBI-V1 daily fields are specified at lateral open boundaries. As IBIV1 does not include tidal forcing and atmospheric pressure forcing, these signals are added at the open boundaries. Tidal elevations and currents of 11 tidal constituents (M2, S2, K2, $\mathrm{N} 2, \mathrm{~K} 1, \mathrm{O} 1, \mathrm{P} 1, \mathrm{Q} 1, \mathrm{M} 4, \mathrm{Mf}, \mathrm{Mm}$ ) are provided from the TPXO7.1 global tide model (Egbert et al., 1994) and applied using Dirichlet boundary conditions. Elevations due to atmospheric pressure static effects, also known as inverse barometer effects (Wunsch and Stammer, 1997), are computed from the ECMWF pressure fields.

Regarding the operational protocol, the system does not include any data assimilation, and the downscaling methodology used here and depicted in Fig. 6 is inherited from the strategy developed and tested in the area for the ESEOAT system (Sotillo et al., 2007). Every week, the regional system is initialized in the past from analysed outputs (3-D temperature, salinity velocities and sea-level) taken from the PSY2 system and bi-linearly interpolated on the refined grid. The model is then integrated until D0 to allow the spin up of small scales and the convergence of physical processes that are not resolved by the parent system. The analysed output at D0 is then used to provide one week forecasts until the next analysis stage. It is worth noting that in the future operational context, the scenario will be somehow different: to account for the best available atmospheric forcing, a 5-day forecast will be performed every day from D0 to D $0+5$.

In order to study the impact of the duration of the spinup phase on the forecasts results, some tests were performed 
Table 3. Description of regional IBIROOS-V2: IBI36. Differences between V2 and V1 versions are written in bold characters.

\begin{tabular}{|c|c|}
\hline \multicolumn{2}{|l|}{ REGIONAL IBIROOS-V2: IBI36 } \\
\hline Domain & $\begin{array}{l}\text { North East Atlantic: } \\
20^{\circ} \mathrm{W}-17^{\circ} \mathrm{E} / 26-64^{\circ} \mathrm{N}\end{array}$ \\
\hline \multicolumn{2}{|l|}{ PHYSICS } \\
\hline Calculation Code & NEMO 2.3 (Primitive Equations) (Madec et al., 2008) \\
\hline Output frequency & Daily 3-D variables + hourly 2-D surface variables (SST, SSH and surface current) \\
\hline Horizontal grid & Tripolar ORCA grid at $1 / 36^{\circ}$ horizontal resolution (approx. 2 km) \\
\hline Vertical grid & $\begin{array}{l}\text { - } 50 \text { geopotential levels ( } 1 \text { to } 480 \mathrm{~m} \text { ) } \\
\text { - Explicit non-linear free surface (Variable Volume Level, Levier et al., 2007; } \\
\text { Griffies and Pacanowski, 2001) } \\
\text { - Partial bottom cells }\end{array}$ \\
\hline Bathymetry & $\begin{array}{l}\text { Mixed local bathymetries: GEBCO 0.8, IFREMER (Esturies and Med Sea (MED- } \\
\text { IMAP)), SHOM (Biscay), BODC (Irish and Celtic Seas), IOW (Baltic), SHOM- } \\
\text { Portugal } \\
\text { (Portugese coasts) }\end{array}$ \\
\hline Surface Forcings & $\begin{array}{l}\text { - Bulk formula: CORE (Large and Yeager, 2004) } \\
\text { - 3-hourly ECMWF analysis \& forecasts } \\
\text { - Surface pressure (surge component) included } \\
\text { - } 35 \text { climatological, monthly river inflows (GRDC + French Hydrobase datasets) } \\
\text { - Short wave radiation penetration with } 2 \text { band scheme and variable climatological } \\
\text { PAR absorption depth }\end{array}$ \\
\hline Boundary Conditions & $\begin{array}{l}\text { Daily open boundary data }(u, v, T, S, \mathbf{S S H}) \text { from Mercator PSY2V3 North Atlantic } \\
\text { system: } \\
\text { - Barotropic variables: characteristic method (Blayo et al., 2005), } \\
\text { - Baroclinic velocities and tracers: } 30 \text {-pts relaxation (1-day timescale) }\end{array}$ \\
\hline Lateral Friction & Partial slip lateral boundary condition \\
\hline Bottom Friction & Logarithmic bottom friction \\
\hline Horizontal Diffusion for the Dynamics & Biharmonic horizontal mixing \\
\hline Horizontal Diffusion for the Tracers & None \\
\hline Vertical Mixing & K-epsilon (Umlauf and Burchard, 2003) \\
\hline Advection & QUICKEST+ULTIMATE (Leonard, 1979, 1991) \\
\hline Tide & $\begin{array}{l}11 \text { harmonical constituents initially adjusted from TPXO7.1 and FES2004 at open } \\
\text { boundaries, tidal potential }\end{array}$ \\
\hline \multicolumn{2}{|l|}{ BIOLOGY } \\
\hline & No Biology \\
\hline \multicolumn{2}{|l|}{ ASSIMILATION } \\
\hline Method & None for the moment \\
\hline
\end{tabular}

using 1, 2, 3 and 4 week spin-up durations. These test helped to determine the best choice for the spin-up time period.

Figure 8a, b, c and d shows the RMS of the Sea Surface Temperature difference between high resolution satellitebased observations (L3 multi-sensor product from MétéoFrance CMS center in Lannion, France) and the model, for
1, 2, 3 and 4-week spin-up simulations (resp.), for the period May-June 2009, for the Bay of Biscay and the Channel region. In the 1-week spin-up simulation case, the largest errors occur in the Channel and along the shelf break, linked with the tide dynamics, and north of the Galicia coast probably due to the initialization temperature field. From the 


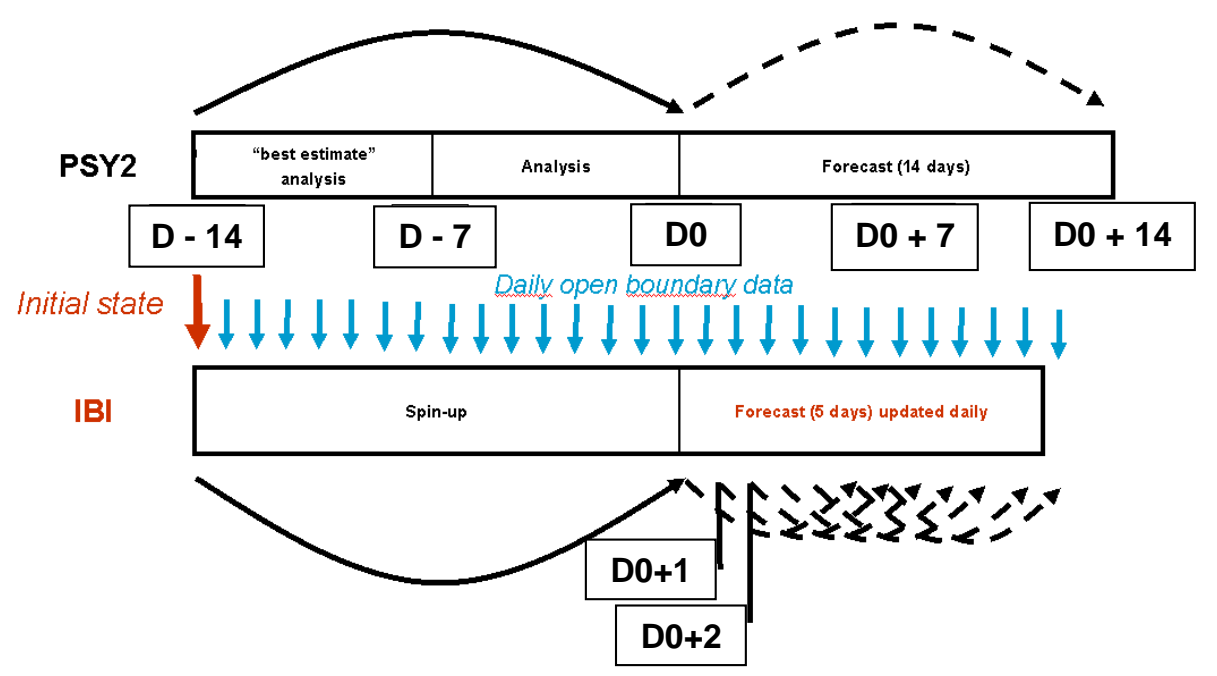

Fig. 6. Operational protocol scheme for V2 system.

2-week spin-up simulation, substantial errors decrease in the Channel. The RMS error pattern north of Galicia has disappeared. The RMS error is also reduced over the French shelf. On the other hand, the RMS error is slightly increased along the shelf break probably due to a lack of internal tides mixing; it also increases close to the Landes coast. So, in some specific areas where the tides are important or in frontal zones, a longer spin-up time would be necessary to reduce the RMS error.

Figure 8e shows the RMS error evolution for different regions (GLOB, IBER, NSEA, BOBI and MEDI domains depicted in Fig. 7) and for each IBI36 simulations (from 0 to 4 weeks spin-up). As expected, the RMS decreases strongly with the 1-week spin-up simulation (except in the Mediterranean Sea) thanks to the improved physics of the model compared to the parent model. Then, the model drifts and the RMS error tends to slightly increase (except in the Bay of Biscay region).

Finally, the choice of a 2-week spin-up for IBI-V2 seems to be the best compromise to answer the technical operational constraints, to constrain the mesoscale structures from the assimilated embedding basin system (PSY2V3) and to allow the own dynamics of the regional model which is not resolved by the embedding system to establish. Indeed, from about 1-month spin-up, the memory of mesoscale structures is lost. Besides, the time characteristic of the tidal adjustment and so the occurrence of tidal fronts is in the order of 2 weeks. And we can note that some biases of embedding system, such as the bias off Galician coasts (North-West of Spain), disappear as from a 2 week spin-up.

\section{Validation and V2 vs. V1 comparisons}

First, this paper will follow a qualitative approach and validate the representation of different regional physical processes in the IBI area. Then, a more quantitative study is performed. Most of the diagnostics shown correspond to the operational simulation IBI-V2-OPER, which follows the operational protocol previously described. Nevertheless, some diagnostics from a 2-yr continuous free simulation IBI-V2CONT (from June 2007 to July 2009) are also used. By default, when IBI-V2-CONT is not specified in the text, IBI-V2 refers to the IBI-V2-OPER set-up.

\subsection{Qualitative validation}

\subsubsection{Thermal fronts}

From Sea Surface Temperature (SST) gradients, the position of thermal fronts can be estimated simply. In order to compare directly model results and observations, the data was interpolated in space and time SST model onto the observational grid. We then calculate the temperature gradient along the $\mathrm{x}$ - and $\mathrm{y}$-axis and sum their norms. Finally, we map the maximum gradients for the model and the observations, as seen in Fig. 9 in the English Channel and Celtic Sea region. These fronts are located at the boundaries between stratified areas and mixed areas, where tides interact with bathymetry. On 24 June 2009, the IBI-V2 simulation and satellite-based observations (L3 multi-sensor from Météo France CMS) show very similar outcomes (Fig. 9). Almost all the main fronts are reproduced at the right position by the model, along the Brittany coast, across the English Channel, or along the Cornwall coast. The main discrepancy comes from the front crossing from Ireland to Wales: this front goes deep into the Irish Sea in the IBI-V2 simulation. This is not the case with a 4 -week spin-up simulation test 


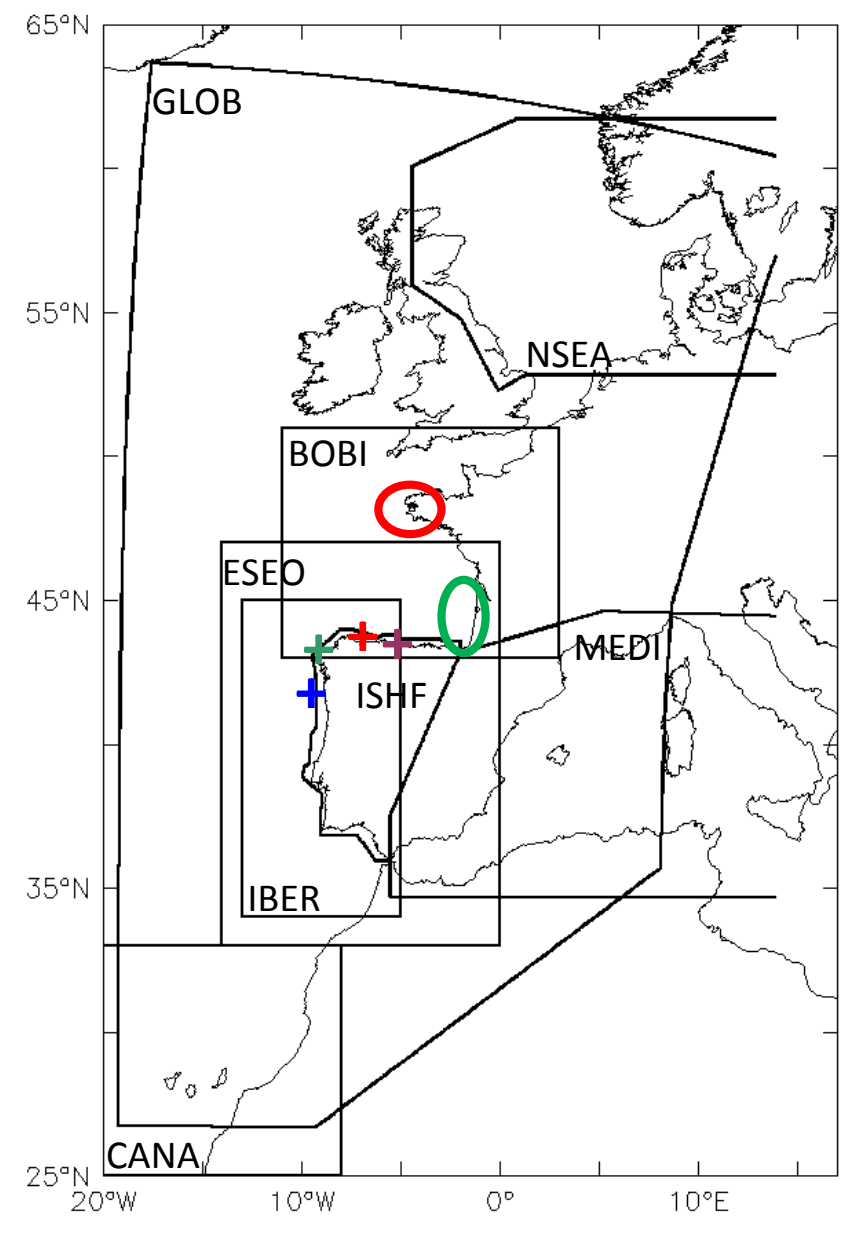

Fig. 7. Map of IBI area with boxes where statistics have been calculated: Bay of Biscay region (BOBI: $11^{\circ} \mathrm{W}-3^{\circ} \mathrm{E}, 43-51^{\circ} \mathrm{N}$ ), the Canary Islands region (CANA: $21-8^{\circ} \mathrm{W}, 25-33^{\circ} \mathrm{N}$ ), the ESEOAT region (ESEO: $14^{\circ} \mathrm{W}-0^{\circ} \mathrm{E}, 33-47^{\circ} \mathrm{N}$ ), the Iberic Peninsula region (IBER: $13-5^{\circ} \mathrm{W}, 34-45^{\circ} \mathrm{N}$ ), the Iberic Peninsula shelf region (ISHF: IBER region over the shelf), the Mediterranean Sea region (MEDI: from Gibraltar strait to $9^{\circ} \mathrm{E}$ ), the North Sea region (NSEA: $12^{\circ} \mathrm{W}-14^{\circ} \mathrm{E}, 48-62^{\circ} \mathrm{N}$ ) and the IBI domain region (GLOB). The colored crosses corresponds to the moorings: Cabo Silleiro in blue $\left(9.39^{\circ} \mathrm{W}, 42.13^{\circ} \mathrm{N}\right)$, Villano-Sisargas in green $\left(9.21^{\circ} \mathrm{W}, 43.5^{\circ} \mathrm{N}\right)$, Estaca de Bares in red $\left(7.62^{\circ} \mathrm{W}, 44.06^{\circ} \mathrm{N}\right)$, Cabo de Penas in brown $\left(6.17^{\circ} \mathrm{W}, 43.74^{\circ} \mathrm{N}\right)$. The red circle corresponds to the area of the Ushant front and the green one corresponds to the Aquitaine and the Landes coasts.

instead of 2 (not shown), which indicates that for this area a longer spin-up period is necessary to correctly reproduce the tidal dynamics. The IBI-V1 simulation, which does not include any tidal processes, cannot reproduce the fronts.

The Ushant front, off the Brittany coast, is carried out from the interaction between bathymetry and tidal currents. In summer, close to this coast, the tide is weak and water column is well stratified. Further from the coast, tidal currents are strong and the bottom is not deep: so the bottom friction mixes the whole water column. Further out at sea, the bot- tom is deep and the water stays stratified. Thus the colder homogeneous water between both well stratified water areas brings about a strong front in the surface layer. Figure 10 shows a comparison of measured SST (L3 multi-sensor from Météo France CMS), V2 and V1 system SSTs on June 2009: two cold cores of water around the Sein and Ushant islands can be identified in the observations and in the V2 system. The Ushant front cannot be represented by the V1 system which does not include the tidal dynamics.

\subsubsection{Water masses and stratification}

The salty Mediterranean waters flow through the Gibraltar straight, deepen between 1100-1300 m levels to spread in the North eastern Atlantic. Figure 11 shows the yearly mean profile of salinity: the Mediterranean water layer is at about 900-1100 m deep in the V2 system (IBI-V2-CONT simulation) against $700-900 \mathrm{~m}$ in V1. Therefore these waters are better deepened in V2 but they are too salty compared with climatology.

In order to validate stratification over the Bay of Biscay shelf, we use the in situ profile measurements from the PELGAS 2009 oceanographic cruise (IFREMER; the data have been extracted from data holdings at the SISMER data centre) carried out in the Bay of Biscay in May 2009 for comparisons with IBI-V2 and V2 systems. The data are irregularly distributed in space and time and we used a collocalisation tool (adapted from Juza 2008) to build modeled profiles at the same location and same day as observed profiles. Observed and modeled profiles are then interpolated on a 3-D grid for visualization. Figures 12 and 13 present the interpolated temperature and salinity fields for the observations, the IBI-V2 and the V1 systems. Each profile's date is different so the fields are not snapshots of a particular day but for the whole period of May 2009. The ship track goes from the South to the North. At the end of May, more measurements were made again in the South of the shelf (the results of this part of the cruise are presented in a separated little window). The observed thermal stratification shows two minima (Fig. 12). One along the Aquitaine coast: the measurements were made in this area at the beginning of May when the thermal stratification is not yet established; surface waters in this area can also be influenced by the Gironde plume. The other minimum is observed west of the Brittany coast, in the Ushant front; in this area, the thermal stratification cannot be set up due to the strong tidal mixing. A maximum of thermal stratification is observed near $47^{\circ} \mathrm{N}, 2.5^{\circ} \mathrm{W}$. At the end of May (small window on Fig. 12) the thermal stratification is set up and differences between surface and bottom can reach $5^{\circ} \mathrm{C}$ over the shelf. The IBI simulation is close to the observations, as the minimum and maximum are well reproduced. The thermal stratification is slightly overestimated offshore at the $200 \mathrm{~m}$ isobath. The IBI-V1 simulation, which does not use tidal forcing, is not able to reproduce the minimum of stratification in the Ushant front. The 

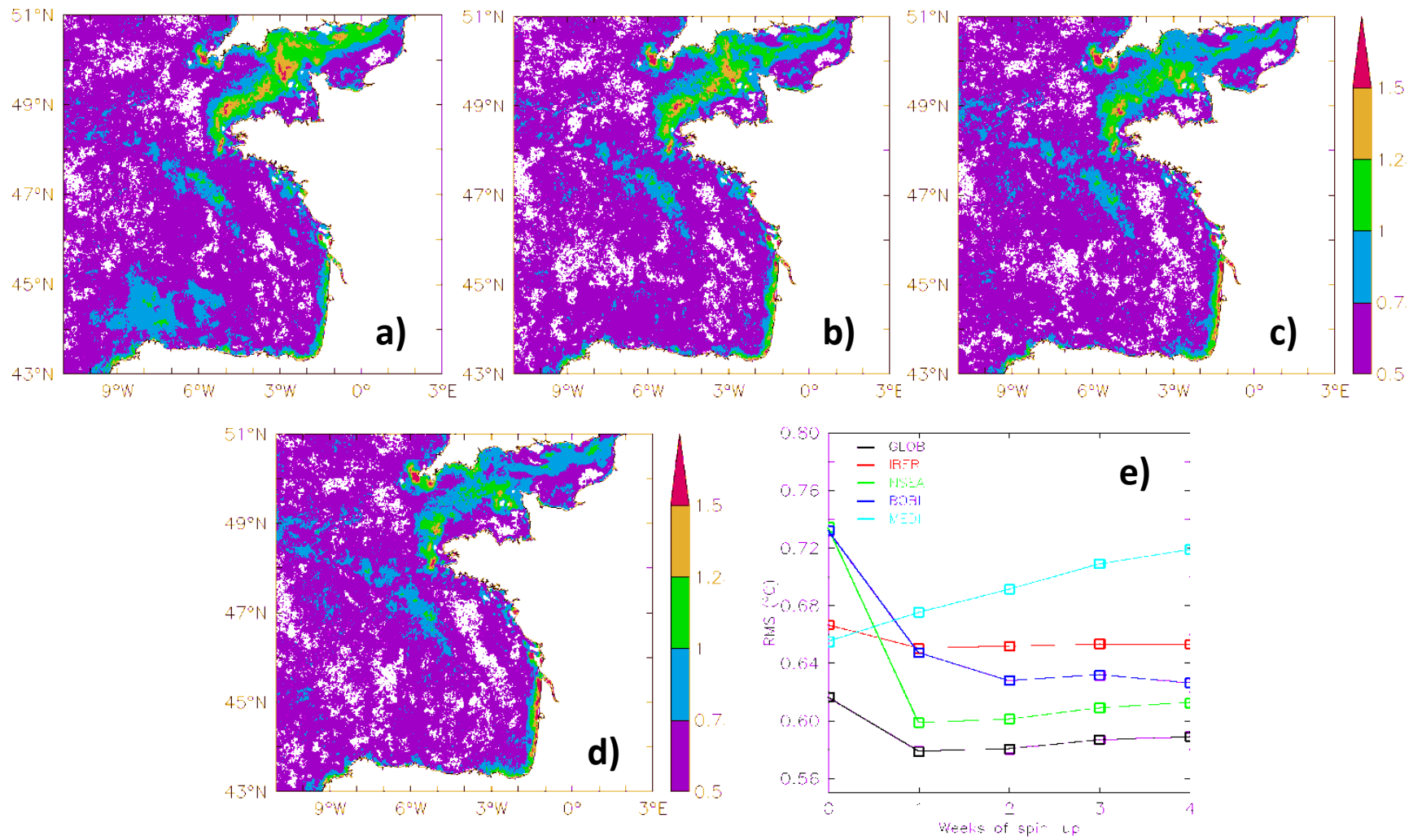

Fig. 8. (a), (b), (c) and (d): RMS (observation minus model) Sea Surface Temperature (SST) difference $\left({ }^{\circ} \mathrm{C}\right)$ for the period May-June 2009 for the 1, 2, 3 and 4 weeks spin-up IBI simulations (resp.), for the Bay of Biscay and Channel region. (e): spatial average RMS (observation (CMS) minus model) SST difference $\left({ }^{\circ} \mathrm{C}\right.$ ) for the period May-June 2009 for the 0 to 4 weeks spin-up IBI36 simulations, for the regions GLOB, IBER, NSEA, BOBI and MEDI presented in Fig. 7.
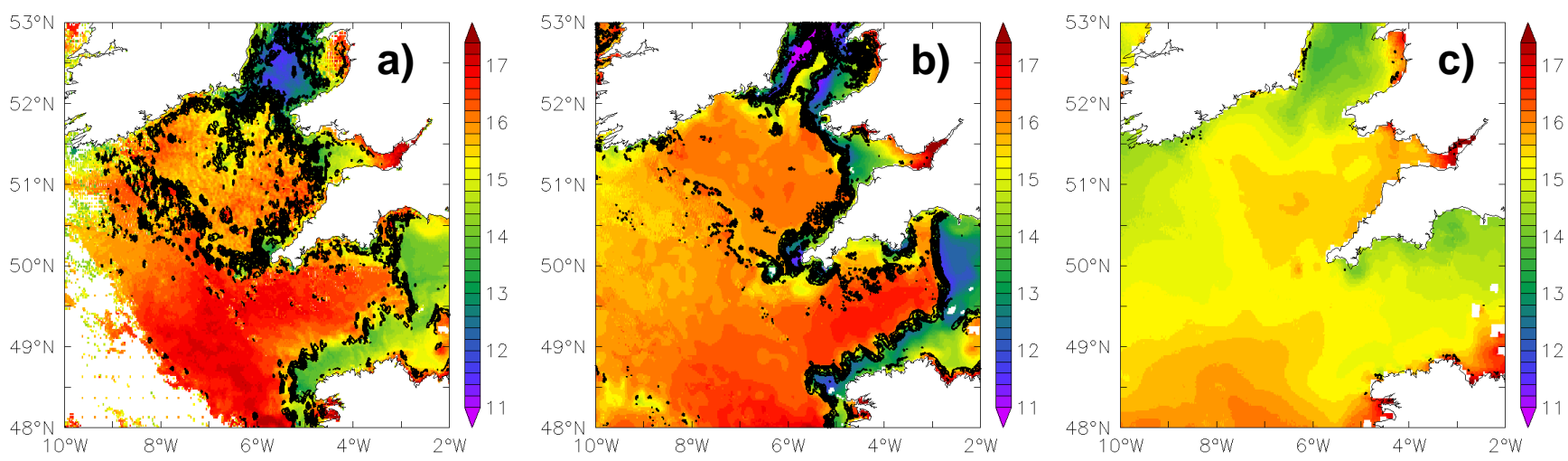

Fig. 9. Sea surface temperature $\left({ }^{\circ} \mathrm{C}\right)$ on 24 June with maximum horizontal gradients of SST overlaid for observation (a), V2 system (b) and V1 system (c).

thermal stratification is too weak for these two simulations. The observed haline stratification (Fig. 13) shows an alongshore gradient over the shelf with a maximum in the Gironde estuary, a secondary maximum near the Loire estuary, and a minimum near Brittany. The difference between surface and bottom salinity is negative all over the shelf up to Brittany. This is due to the river plumes which spread over the shelf.
In the southern part of the shelf, the IBI-V2 simulation reproduces the haline stratification pattern, but the Gironde estuary maximum is under-estimated contrary to IBI-V1 simulation. The positive difference near Brittany and offshore at the $200 \mathrm{~m}$ isobath is not reproduced. However, the IBIV2 simulation slightly improves the results compared to the IBI-V1 one by which it was initialized. Figure 14 completes 

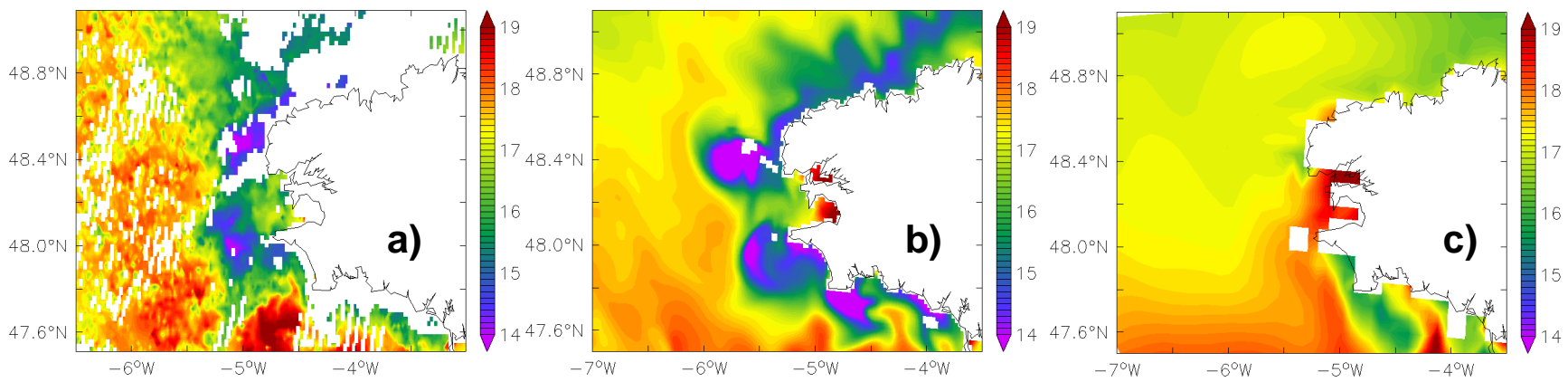

Fig. 10. Ushant front off French Britain coast (9 July 2011) (a) MF_CMS SST; (b) V2 system SST; (c) V1 system SST.

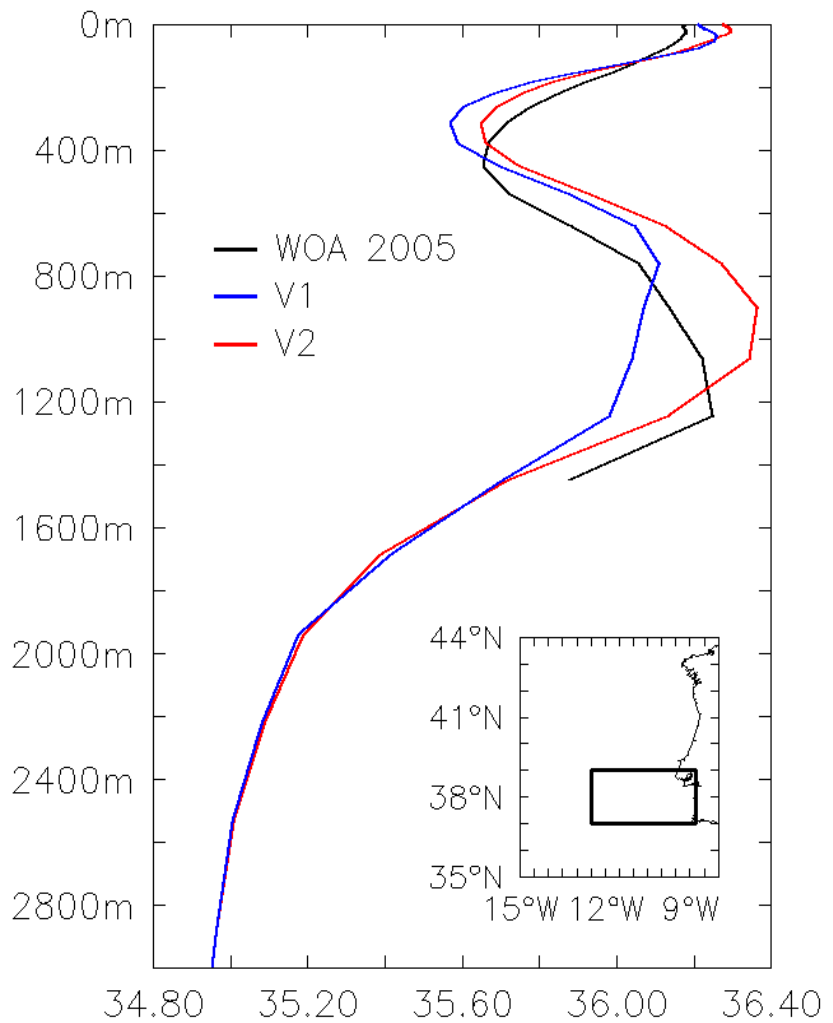

Fig. 11. 2009 annual mean salinity profile off Spanish coast: black line for WOA 2005 climatology (http://www.nodc.noaa.gov/OC5/ WOA05/pr_woa05.html), blue line for V1 system (IBI36-CONT) and red line for V2 system.

this stratification analysis by showing temperature and salinity profiles on May 2009 for the same PELGAS period as considered previously. The temperature profile of IBI-V2 is colder and therefore closer to the observation than IBI-V1 probably due to the new parameterization of solar penetration which takes into account suspended particles by using ocean color data. Regarding salinity profiles, the improvement of IBI-V2 in the fifteen first meters could be explained by a better representation of river plumes.
Table 4. Spatial average (observation minus model) Sea Surface Temperature difference $\left({ }^{\circ} \mathrm{C}\right)$ (left), correlation (middle) and RMS (observation minus model) SST error $\left({ }^{\circ} \mathrm{C}\right.$ ) (right) for the period May-June 2009 in the different regions presented in Fig. 7. Best scores are in bold. We subtracted the linear trend of the time series before calculating the correlations.

\begin{tabular}{|c|c|c|c|c|c|c|}
\hline & \multicolumn{2}{|c|}{ Difference $\left({ }^{\circ} \mathrm{C}\right)$} & \multicolumn{2}{|c|}{ Correlation } & \multicolumn{2}{|c|}{ RMS error $\left({ }^{\circ} \mathrm{C}\right)$} \\
\hline & IBI36 & PSY2v3 & IBI & PSY2v3 & IBI & PSY2v3 \\
\hline BOBI & -0.03 & 0.30 & 0.52 & 0.43 & 0.63 & 0.73 \\
\hline CANA & -0.08 & 0.05 & 0.64 & 0.52 & 0.59 & 0.55 \\
\hline ESEO & -0.07 & 0.25 & 0.55 & 0.49 & 0.61 & 0.65 \\
\hline IBER & -0.08 & 0.19 & 0.53 & 0.47 & 0.65 & 0.67 \\
\hline ISHF & -0.19 & 0.03 & 0.48 & 0.44 & 0.89 & 0.84 \\
\hline MEDI & -0.11 & -0.04 & 0.65 & 0.65 & 0.69 & 0.66 \\
\hline NSEA & -0.11 & 0.23 & 0.70 & 0.64 & 0.60 & 0.73 \\
\hline GLOB & -0.07 & 0.16 & 0.59 & 0.53 & 0.58 & 0.62 \\
\hline
\end{tabular}

As a conclusion, the IBI-V2 system's ability to reproduce haline stratification is reduced by its initial conditions. The thermal stratification is quite well reproduced, despite the problem in the Gironde plume near field due to a very strong mixing. It would have been interesting to fully validate the seasonal stratification in this area by considering winter time too, but PELGAS data do not cover the whole of 2009.

To complete the previous validation of the representation of the water mass and the stratification in the abyssal plain as well as on the shelf, we consider now water masses along the shelf break. The Navidad current is an advection of warm water mass triggered on December. It flows northward along the shelf break in the Bay of Biscay during the winter. Figure 15 shows a comparison of measured SST (AVHRR), V2 and V1 system SSTs on January 2008: the spreading of Navidad along the shelf break as well as its intensity is far better reproduced for V2 system than V1.

\subsection{Quantitative validation}

Figure 16 shows a map of SST bias between satellite-based observations (Météo France CMS L3 multi-sensor SST) and model outputs for the May-June 2009 period. Compared to 

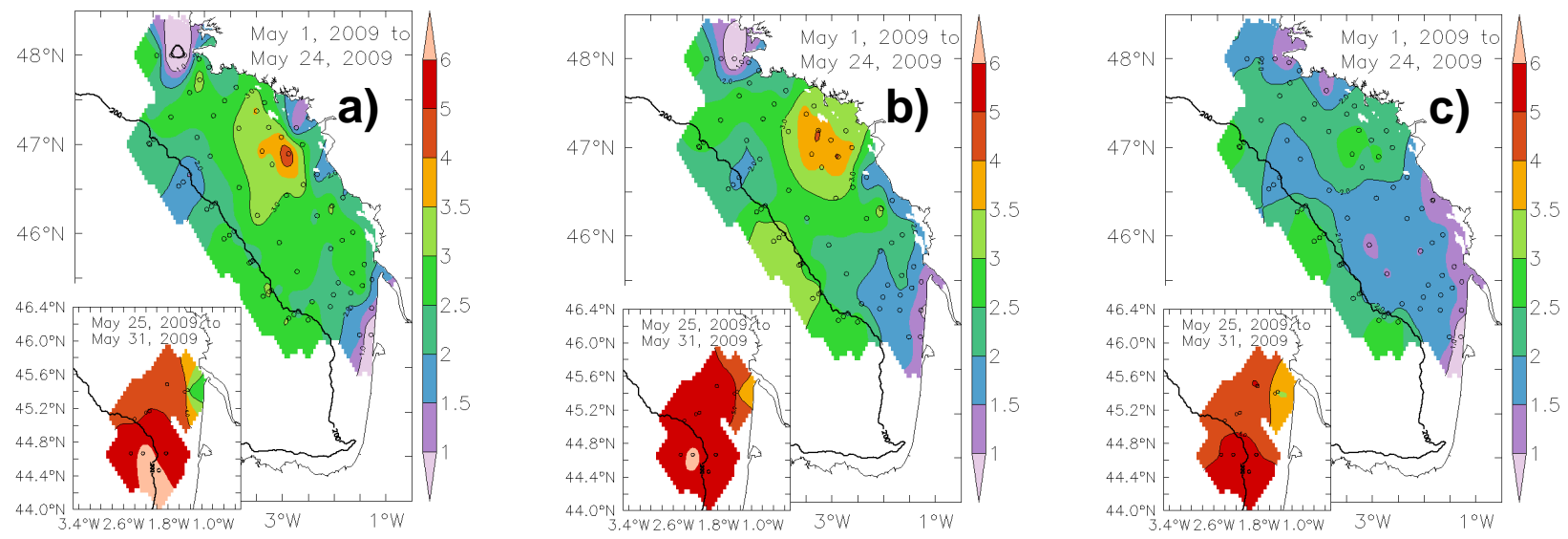

Fig. 12. Surface minus near bed temperature difference $\left({ }^{\circ} \mathrm{C}\right.$ ) for observation (panel a), V2 system (panel b) and V1 system (panel c).
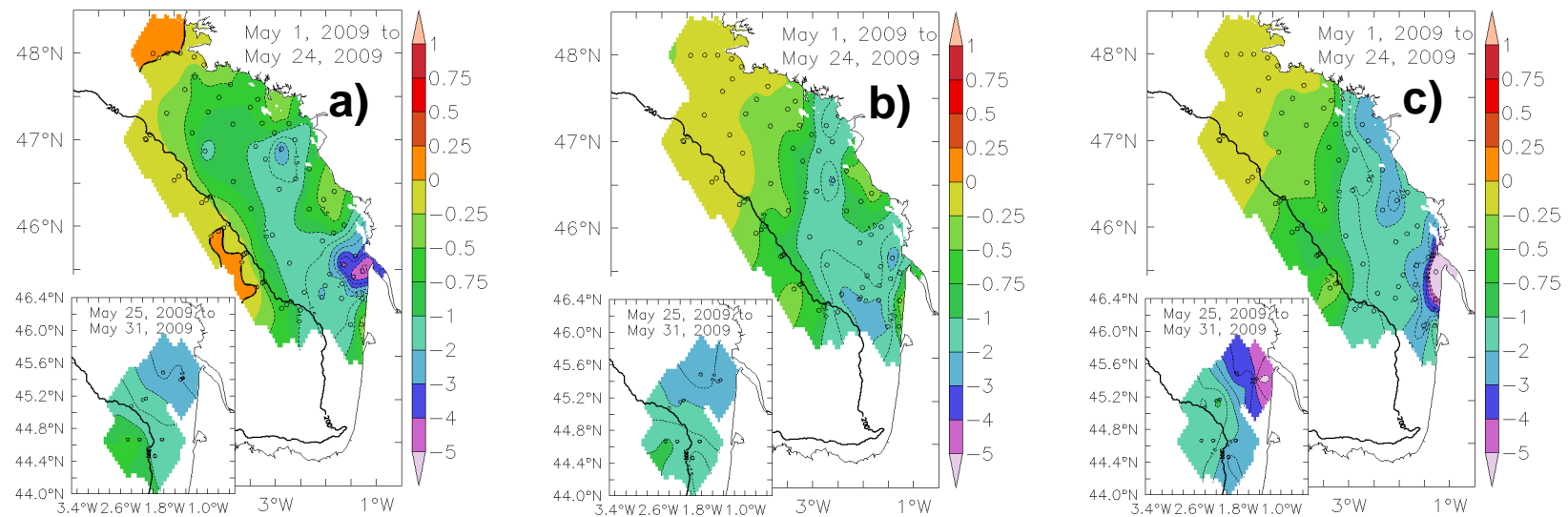

Fig. 13. Same as previous figure but for salinity (psu).

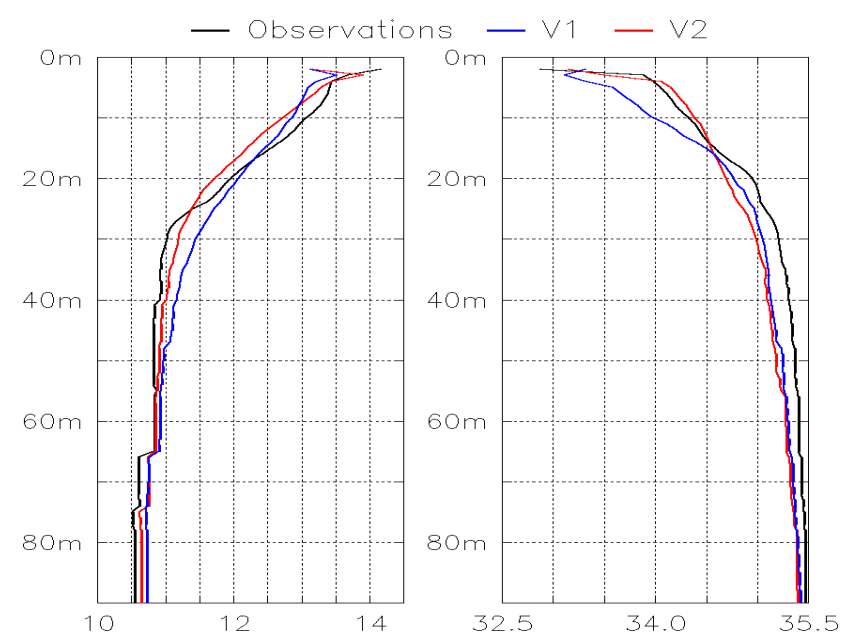

Fig. 14. Mean temperature (on the left) and salinity (on the right) profiles from 0 to $100 \mathrm{~m}$ of depth for observations (black line), V1 (blue line) and V2 (red line)and for the period from 1 to 24 May 2009. The area corresponds to the shelf covered by PELGAS data showed in Figs. 12 and 13.
IBI-V1, the new IBI-V2 system reduces the errors almost everywhere, except along the shelf slope, around the Cape St Vincent, between the Capo Verde islands and the Moroccan coast. The improvement is obvious on the Armorican shelf and in the North Sea. Table 4 gathers statistics calculated for both models for different areas of the IBI region; the IBI-V2 model has most of the best scores.

Regarding residual currents, we compare model currents with observed current measurement time series from the Puertos del Estado deep sea water Network (Alvarez Fanjul et al, 2002; http://www.puertos.es). The buoys considered hereafter are located off the Spanish North-Western coasts near the shelf break: Cabo Silleiro $\left(9.39^{\circ} \mathrm{W}, 42.13^{\circ} \mathrm{N}\right)$, Villano-Sisargas $\left(9.21^{\circ} \mathrm{W}, 43.5^{\circ} \mathrm{N}\right)$, Estaca de Bares $\left(7.62^{\circ} \mathrm{W}, 44.06^{\circ} \mathrm{N}\right)$, Cabo de Peñas $\left(6.17^{\circ} \mathrm{W}, 43.74^{\circ} \mathrm{N}\right)$ as indicated in Fig. 7. As the tide is not taken into account by IBI-V1, the daily residual current was preferred to the total one, to ease the comparison between $\mathrm{V} 1$ and V2. In order to remove the tidal signal from the current time series, we perform a harmonic analysis of the IBIV2 outputs, but not on the IBI-V1 data which does not include the tidal forcing and which outputs are daily averaged. 

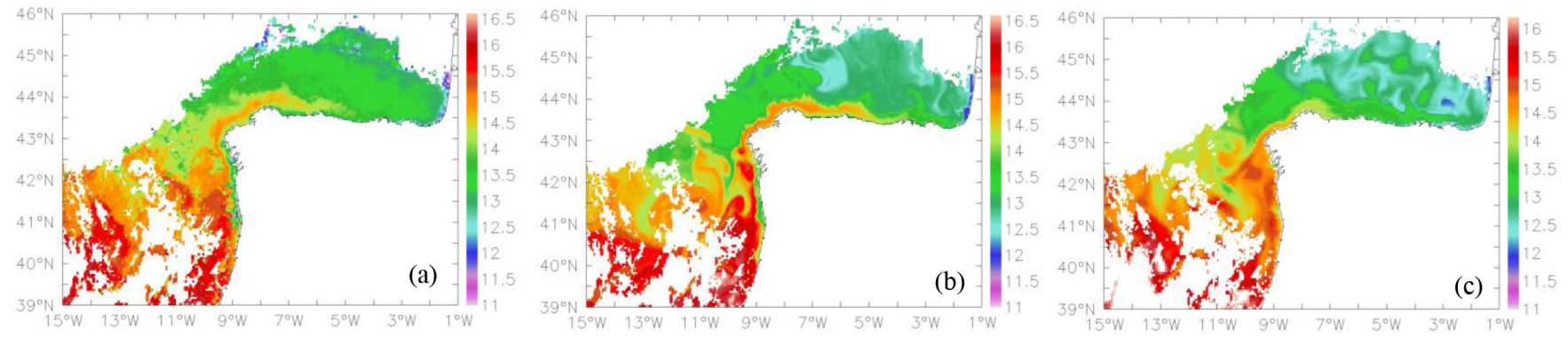

Fig. 15. Navidad: surface warm current along Spanish and French coasts. (a) AVHRR SST; (b) V2 system (IBI-V2-CONT) SST; (c) V1 system.
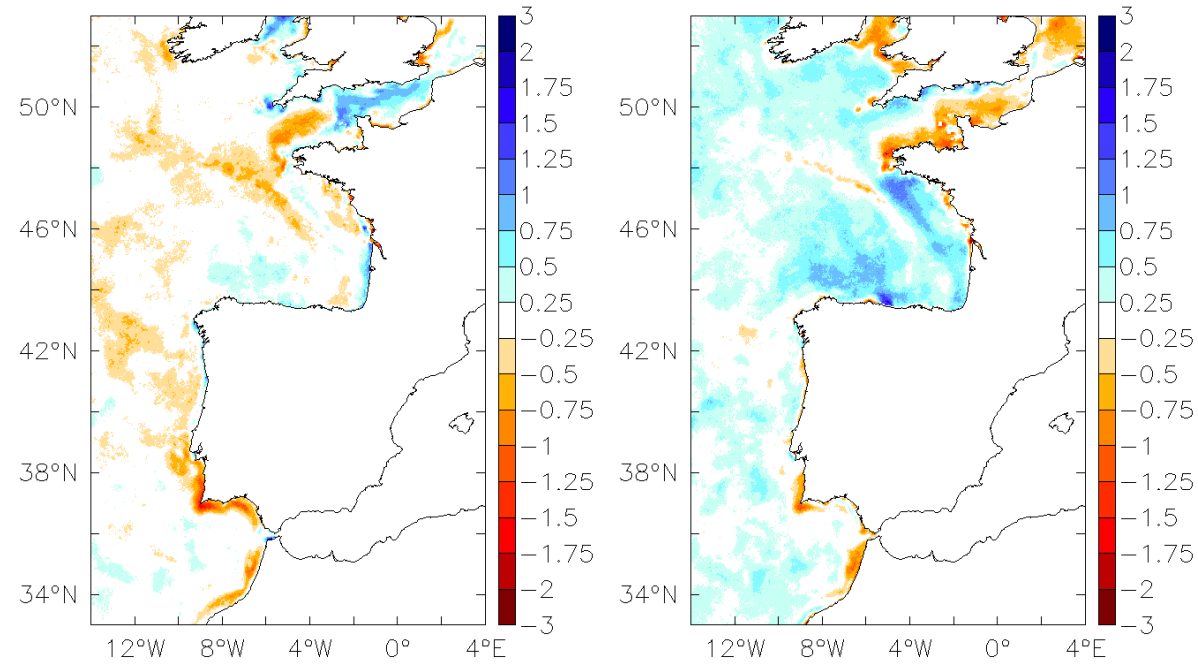

Fig. 16. (observation minus model) Sea Surface Temperature difference $\left({ }^{\circ} \mathrm{C}\right)$ for the period May-June 2009 (left) for V1 system, (right) V2 system. Observations come from CMS L3S SST. The Mediterranean Sea is masked.

Figure 17 represents the zonal and meridional components of the near surface residual current (hourly measurements, one-day filtered and smoothed) at the Cabo Silleiro buoys. This buoy is located on the Spanish west coast (north of the Portuguese border) above the continental slope (above the $600 \mathrm{~m}$ isobath) which is oriented north-south, so the meridional component is equivalent to the along-shore component, and the zonal component is equivalent to the cross-shore component. During the May 2009 period, IBI-V2 system is well correlated with observed measurements, especially for the cross-shore component. The along-shore component is under-estimated by IBI-V2. Table 5 presents the RMS error as well as de-trended correlation for the zonal and meridional components of the current at different locations. The RMS error is calculated with IBI-V2 hourly currents and IBI-V1 daily currents. RMS error is reduced in IBI-V2. Regarding correlation, it is more difficult to conclude: correlations are generally weak, and IBI-V2 does not seem to perform better than IBI-V1. In the Cabo Peñas mooring, the simulated meridian component of current at $3 \mathrm{~m}$ is uncorrelated with data for IBI-V2 (8\%) and it is uncorrelated for IBI-V1 $(-31 \%)$.
Table 5. RMS difference and correlation observation-model for zonal/meridional component of currents at $3 \mathrm{~m}$ depth for the period May-June 2009 at different buoys (presented in Fig. 7). Statistics for IBI36 is calculated with 1 day filtered residual currents. Statistics for PSY2v3 is calculated with daily averaged currents. Best scores are in bold.

\begin{tabular}{lcccccc}
\hline & \multicolumn{2}{c}{ RMS $\left(\mathrm{cm} \mathrm{s}^{-1}\right)$} & & \multicolumn{2}{c}{ Correlation $(\%)$} \\
\cline { 2 - 3 } \cline { 6 - 7 } & IBI36 & PSY2v3 & & IBI36 & PSY2v3 \\
\hline Cabo Penas & $\mathbf{7 / 7}$ & $18 / 9$ & & $\mathbf{7 3 / 8}$ & $54 /-31$ \\
Cabo Silleiro & $\mathbf{5 / 9}$ & $8 / 10$ & & $\mathbf{6 7 / 3 9}$ & $56 / 67$ \\
Estaca bares & $\mathbf{9 / 5}$ & $22 / 10$ & & $52 / 72$ & $\mathbf{6 9 / 2 4}$ \\
Villano Sisargas & $\mathbf{1 1 / 9}$ & $14 / 9$ & & $40 / \mathbf{4 0}$ & $\mathbf{4 9 / 2 5}$ \\
\hline
\end{tabular}

\section{Conclusion and prospects}

This paper has presented the 3-version evolution of the regional IBI ocean forecasting system of Mercator Ocean in the framework of ECOOP project and has shown the improvement of the downscaling from the regional IBI system 

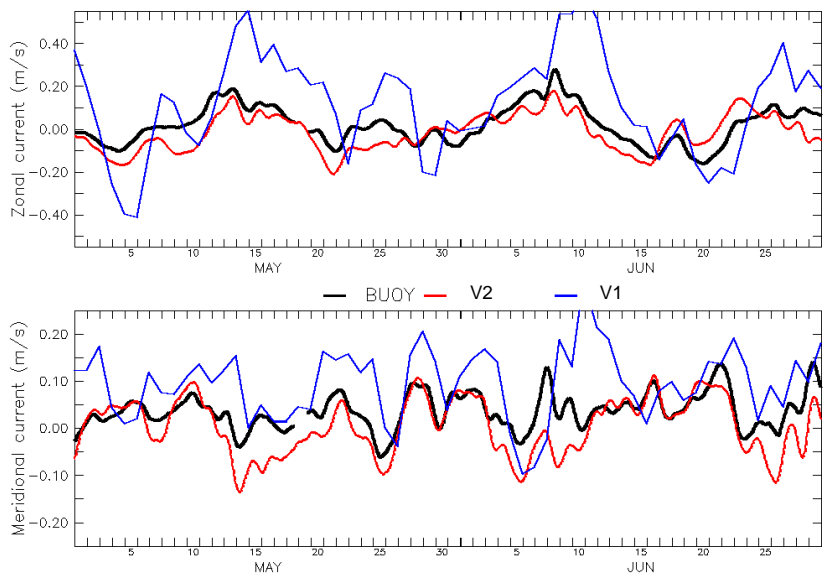

Fig. 17. Time series of zonal (top) and meridional (bottom) components of the current $\left(\mathrm{m} \mathrm{s}^{-1}\right)$ at $3 \mathrm{~m}$ depth for the period MayJune 2009 at Estaca de Bares buoy (North-West Spanish coast near Capo Finisterra: see Fig. 7). Observation is in black, V2 system in red and V1 system in blue. Residual current on May-June 2009 at the mooring Estaca de Bares (North-West Spanish coast near Capo Finisterra: see Fig. 7).

to coastal systems of the other European partners. The regional system must consider both deep sea and shelf sea physics features, in order to provide quite reliable boundary and initial conditions to the embedded coastal systems. Thus, strong efforts were made in order to include further coastal physics in the NEMO code, which was normally used to simulate larger scales processes. Now 11 tidal components can be taken into account thanks to a new non-linear free surface, the time splitting which permits to separate high frequency barotropic signals from baroclinic ones, and new formulations of open boundary conditions. High frequency 3-hourly atmospheric fluxes have been used to force surface model. And a merged bathymetry has been generated from different regional data basis. The $1 / 36^{\circ}$ horizontal resolution (2-3 km at these latitudes) which allows the model to resolve mesoscale and sub-mesoscale structures, specially improves the representation of local front areas. For the operational scenario, the system is initialized by PSY2V3 (and soon PSY2V4, its upgrade). All these developments have allowed the model to adapt to coastal dynamics.

In a second part, this paper has shown the validation of the last version IBI-V2 system against data and the previous version IBI-V1. In general, the validation of an operational system is not an easy issue. A system is never assessed enough, especially in a large regional system such as IBI which gathers a lot of local physical processes and even different physical regimes between shelves and abyssal plain areas. Here, this paper is not intended as a validation report, so we have selected only the main thermo-dynamical features and which were assessed in a qualitative and quantitative way by using the little available observation data.
We have distinguished on the one hand a qualitative validation which has directly compared simulation outputs to some known physical characteristics in IBI area, and on the other hand a quantitative validation where current time series and statistical scores have been compared.

A better representation of frontal zones in the IBI-V2 system vs. V1 shows the impact of the tide in the model. The Ushant thermal front is particularly well represented in the IBI-V2.

IBI-V2 deepens the Mediterranean water between $900 \mathrm{~m}$ and $1100 \mathrm{~m}$ closer to the right depth (1100-1300 m) against IBI-V1 (700-900) but it is too salty vs. the climatology.

A use of in situ data (PELGAS 2009) has allowed the validation of the stratification on the Biscay shelf. The thermal stratification of the IBI system corresponds to data, whereas the haline stratification is further from observations probably because the IBI-V2 system is too influenced by initialization of PSY2V3. The use of climatological monthly runoffs could also play a role.

The Navidad, this warm water advection along the shelf break which occurs in December seems to be far better simulated by IBI-V2 in term of spreading and intensity.

Regarding SST statistics (bias, and RMS and correlations by subregions), the IBI-V2 system has shown globally better results against IBI-V1. Regarding dynamics, the IBI-V2 system currents are better than in IBI-V1.

So to conclude, further regional physics taken into account in the new version V2 have proved a real improvement of results against the previous version $\mathrm{V} 1$.

This new system which has been developed within the ECOOP project is now almost ready to become the V1 version for the latest EU project MyOcean and should better answer the need of coastal modellers (in term of initial and boundary conditions). Following the first conclusions from the validation and in order to improve the system for the V2 version for My Ocean next year, several upgrades have been planned.

We have seen how IBI-V2 forecasts depend on initial conditions provided by the embedding basin system. Each week the regional operational system will be restarted with initial conditions from the new PSY2V4 system. The PSY2V4 system will replace the PSY2V3 system and benefits of many enhancements: use of IAU (Incremental Analysis Update) in the data assimilation algorithm, use of a large bias correction method and ECMWF 3-hourly forcings among other. In particular the incremental analysis update is an efficient way to distribute the correction in time and allows us to restart from an equilibrate state, which was not the case with the PSY2V3 system. This new basin system will provide boundary conditions too. Besides, tests of other operational scenarios with a decreasing influence of initial conditions on shelves should improve the solution in these areas since IBI system physics is more adapted.

Moreover, at the regional scale the wave impact must be better taken into account. As the IBI-V2 system is not 
coupled with a wave model, a first idea consists in forcing with the wind stress processed by the MetNo (Norwegian Met Office) and integrating wave effect. We usually force directly the system by the total air-sea momentum flux which can be split into two terms: one term acting on the mean currents (e.g. flat plate drag) and the other acting on the waves and responsible for wave growth. For the momentum flux that should be applied in the ocean model, there are two sources: the direct effect of the wind and the forcing by dissipating waves. Whenever there is an imbalance between wave growth and dissipation, the mean ocean surface stress will differ from the total air-sea flux. As a result a more realistic vertical mixing should be reached.

Some works about river discharges are planned too. New daily runoffs from a data base used by PREVIMER and real time runoffs modelled by HYPE (from SMHI, Sweden) hydrological models should improve the haline stratification on shelves.

Finally, a part of the large scale sea surface temperature bias seems to be triggered by large scale radiation flux bias. So a test on a correction of ECMWF fluxes with CMS (MeteoFrance) satellite fluxes is also planned and should reduce this bias.

Acknowledgements. This work was supported by the ECOOP project, which was funded by the European Commission's Sixth Framework Program.

Thank you to the LEGOS (Laboratoire d'Etude Geophysique et Océanographie Spatiale, Toulouse, France) for the fruitful discussions.

Edited by: P. Oddo

\section{References}

Alvarez Fanjul, E., Alfonso, M., Ruiz, M. I., López, J. D., and Rodríguez, I.: Real Time monitoring of Spanish Coastal Waters. Proceedings of the Third international conference on Eurogoos: Building the European capability in Operational Oceanography, Elsevier, 2002.

Barnier, B., Siefriedt, L., and Marchesiello, P.: Thermal forcing for a global ocean circulation model using a three-year climatology of ECMWF analysis, J. Marine Syst., 6, 363-380, 1995.

Barnier, B., Madec, G., Penduff, T., Molines, J.-M., Treguier, A.M., Le Sommer, J., Beckmann, A., Biastoch, A., Böning, C., Dengg, J., Derval, C., Durand E., Gulev, S., Remy, E., Talandier, C., Theetten, S., Maltrud, M., McClean, J., and De Cuevas, B.: Impact of partial steps and momentum advection schemes in a global ocean circulation model at eddy-permitting resolution, J. Ocean Dynam., 56, 543-567, doi:1007/s10236-006-0082-1, 2006.

Becker, J. J., Sandwell, D. T., Smith, W. H. F., Braud, J., Binder, B., Depner, J., Fabre, D., Factor, J., Ingalls, S., Kim, S.-H., Ladner, R., Marks, K., Nelson, S., Pharaoh, A., Trimmer, R., Von Rosenberg, J., Wallace, G., and Weatherall, P.: Global Bathymetry and Elevation Data at 30 Arc Seconds Resolution: SRTM30_PLUS, Mar. Geod., 32, 355-371, 2009.
Bernie, D. J., Woolnough, S. J., Slingo, J. M., and Guilyardi, E.: Modelling diurnal and intraseasonal variability of the ocean mixed layer, J. Climate, 18, 1190-1202, 2005.

Blayo, E. and Debreu, L.: Revisiting open boundary conditions from the point of view of characteristic variables, Ocean Model., 9, 231-252, 2005.

Burchard, H.: Simulating the Wave-Enhanced Layer under Breaking Surface Waves with Two-Equation Turbulence Models, J. Phys. Oceanogr., 31, 3133-3145, 2001.

Canuto, V. M., Howard, A., Cheng, Y., and Dubovikov, M. S.: Ocean Turbulence. Part I: One-Point Closure Model - Momentum and Heat Vertical Diffusivities, J. Phys. Oceanogr., 31, 1413-1426, 2001.

Chanut, J., Barnier, B., Large, W., Debreu, L., Penduff, T., Molines, J.-M., and Mathiot, P.: Mesoscale Eddies in the Labrador Sea and Their Contribution to Convection and Restratification, J. Phys. Oceanogr., 38, 1617-1643, 2008.

Craig, P. D. and Michael, L. B.: Modeling wave-enhanced turbulence in the ocean surface layer, J. Phys. Oceanogr., 24, 25462559, 1994.

Dai, A. and Trenberth, K. E.: The Diurnal cycle and Its Depiction in the Community Climate System Model, J. Climate, 17, 930-951, 2004.

Egbert, G., Bennett, A., and Foreman, M.: TOPEX/Poseidon tides estimated using a global inverse model, J. Geophys. Res., 99, 24821-24852, 1994.

Gurgel, K.-W., Antonischki, G., Essen, H.-H., and Schlick, T.: Wellen Radar (WERA): a new ground-wave HF radar for ocean remote sensing, Coast. Eng., 37, 219-234, 1999.

Gaspar, P., Gregoris, Y., and Lefevre, J. M.: A simple eddy-kineticenergy model for simulations of the ocean vertical mixing : test at station papa and long-term upper ocean study site, J. Geophys. Res., 95, 16179-16193, 1990.

Griffies, S. M., Pacanowski, R. C., Schmidt, M., and Balaji, V.: Tracer Conservation with an Explicit Free Surface Method for Zcoordinate Ocean Models, Mon. Weather Rev., 129, 1081-1098, 2001.

Holt, J. and Umlauf, L.: Modelling the tidal mixing fronts and seasonal stratification of the Northwest European Continental shelf, Original Research Article, Cont. Shelf Res., 28, 887-903, 2008.

Juza, M.: Collocation and validation tools for the DRAKKAR ensemble of simulations, Technical report, MEOM-LEGI, Grenoble, 2008.

Large, W. G. and Yeager, S. G.: Diurnal to decadal global forcing for ocean and sea-ice models: the data sets and flux climatologies, NCAR technical notes, 2004.

Leonard, B. P.: A stable and accurate convective modelling procedure based on quadratic upstream interpolation, Comp. Meth. in Appl. Mech. and Eng., 19, 59-98, 1979.

Levier, B., Tréguier, A. M., Madec, G., and Garnier, V.: Free surface and variable volume in the NEMO code. MERSEA IP report WP09-CNRS-STR03-1A, 47 pp., 2007.

Madec, G.: NEMO Ocean General Circulation Model Reference Manuel, Internal Report, LODYC/IPSL, Paris, 2008.

Madec, G., Delecluse, P., Imbard, M., and Lévy, C.: OPA 8.1 Ocean general circulation model reference manual, Institut PierreSimon Laplace, 20, p. 91, 1998.

Mellor, G. L. and Yamada, T.: Development of a turbulence closure model for geophysical fluid problems, Rev. Geophys. Ge., 20 , 
$851-875,1982$.

Oberhuber, J. M.: An atlas based on the "COADS" data set: The budgets of heat, buoyancy and turbulent kinetic energy at the surface of the global ocean, Max-Planck-Institut für Meteorologie, Report 15, Hamburg, Germany, 1988.

Pham, D. T., Verron, J., and Roubaud, M. C.: A singular evolutive extended Kalman filter for data assimilation in oceanography, J. Marine Syst., 16, 323-340, 1998.

Reffray, G., Levier, B., Marsaleix, P., Lazure, P., and Garnier, V.: Intercomparaison de modèles sur le Golfe de Gascogne pour l'année 2004, Rapport SHOM/Mercator Océan, 2008.

Reynaud, T., Legrand, P., Mercier, H., and Barnier, B.: A new analysis of hydrographic data in the atlantic and its application to an inverse modeling study, International WOCE Newletter, 32, 29-31, 1998.
Rodi, W.: Example of calculation methods for flow and mixing in stratified, J. Geophys. Res., 92, 5305-5328, doi:10.1029/JC092iC05p05305, 1987.

Sotillo, M. G., Jordi, A., Ferrer, M. I., Conde, J., Tintoré, J., and Álvarez-Fanjul, E.: The ESEOO Regional Ocean Forecasting System. Proceedings of the seventeenth (2007) International Offshore And Polar Engineering Conference, 1-4, 1716-1722, 2007.

Umlauf, L. and Burchard, H.: A generic length-scale equation for geophysical turbulence models, J. Mar. Res., 61, 235-265, 2003.

Wilcox, D. C.: Reassessment of the scale-determining equation for advanced turbulence models, AIAA Journal (ISSN 0001-1452), 26, 1299-1310, 1988.

Wunsch, C. and Stammer, D.: Atmospheric loading and the oceanic “inverse barometer" effect, Rev. Geophys., 35, 79-107, 1997. 